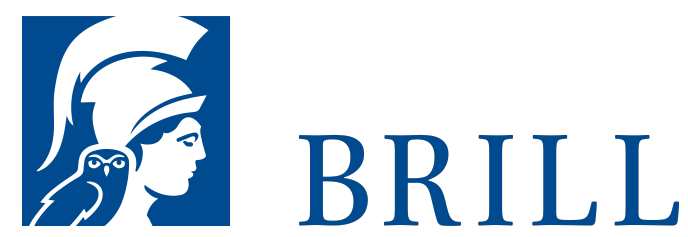

\title{
Index to Periodical Literature on Christ and the Gospels
}

\section{Author: Mills}

This publication updates Bruce Metzger's monumental Index to the present. In addition to all the periodicals indexed by Metzger (where these are still active), this volume updates the list with a number of newer periodicals which had not yet begun publication when Metzger compiled his work. Metzger's original citations $(10.000+)$ are complemented by an additional $4.800+$ new references, using the same basic arrangement employed by Metzger.

\section{Readership}

New Testament scholars and students.

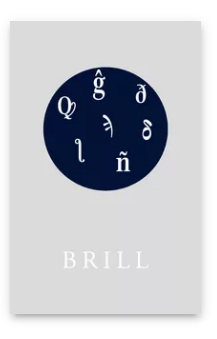

Pages: $\mathrm{xxx}, 962$ pp.

Language: English

Subjects: New Testament \& Early Christian Writings, Biblical Studies Publisher: Brill

\section{Series:}

New Testament

Tools, Studies

and Documents,

Volume: 27

E-Book (PDF)

Released online: 26 Nov 2019

ISBN: 978-90-

04-37996-1

List price

USD $\$ 549.00$

Hardback

Publication date: 3о Sep 1998

ISBN: 978-9004-10098-5

List price USD $\$ 518.00$ 
Watson E. Mills, Ph.D. (1973), Baylor University, is Associate and Professor of New Testament Studies, Mercer University, Macon. His many publications include the updating of Bruce Metzger's Index to Periodical Literature on the Apostle Paul (Brill, 1993).

For more information see brill.com

\begin{abstract}
Order information: Order online at brill.com +44330 333 0049 | customerservices@brill.com Submission information: brill.com/authors
\end{abstract}

Titles published by Brill | Fink, Brill | mentis or Brill | Schöningh: +49(o)71 5413279216 | brill@brocom.de 